Article

\title{
Environmental Sustainability Assessment of Typical Cathode Materials of Lithium-Ion Battery Based on Three LCA Approaches
}

\author{
Lei Wang ${ }^{1}$, Haohui $\mathrm{Wu}^{1}$, Yuchen $\mathrm{Hu}^{1}{ }^{1}$, Yajuan $\mathrm{Yu}^{1, *}$ and Kai Huang ${ }^{2, *}$ \\ 1 School of Materials Science and Engineering, Beijing Institute of Technology, Beijing 100081, China; \\ 3120181158@bit.edu.cn (L.W.); 2120171208@bit.edu.cn (H.W.); 3220180937@bit.edu.cn (Y.H.) \\ 2 College of Environmental Science and Engineering, Beijing Forestry University, Beijing 100083, China \\ * Correspondence: 04575@bit.edu.cn (Y.Y.); huangkai@bjfu.edu.cn (K.H.)
}

Received: 2 January 2019; Accepted: 24 January 2019; Published: 7 February 2019

\begin{abstract}
With the rapid increase in production of lithium-ion batteries (LIBs) and environmental issues arising around the world, cathode materials, as the key component of all LIBs, especially need to be environmentally sustainable. However, a variety of life cycle assessment (LCA) methods increase the difficulty of environmental sustainability assessment. Three authoritative LCAs, IMPACT 2002+, Eco-indicator 99(EI-99), and ReCiPe, are used to assess three traditional marketization cathode materials, compared with a new cathode model, $\mathrm{FeF}_{3}\left(\mathrm{H}_{2} \mathrm{O}\right)_{3} / \mathrm{C}$. They all show that four cathode models are ranked by a descending sequence of environmental sustainable potential: $\mathrm{FeF}_{3}\left(\mathrm{H}_{2} \mathrm{O}\right)_{3} / \mathrm{C}$, $\mathrm{LiFe}_{0.98} \mathrm{Mn}_{0.02} \mathrm{PO}_{4} / \mathrm{C}, \mathrm{LiFePO}_{4} / \mathrm{C}$, and $\mathrm{LiCoO}_{2} / \mathrm{C}$ in total values. Human health is a common issue regarding these four cathode materials. Lithium is the main contributor to the environmental impact of the latter three cathode materials. At the midpoint level in different LCAs, the toxicity and land issues for $\mathrm{LiCoO}_{2} / \mathrm{C}$, the non-renewable resource consumption for $\mathrm{LiFePO}_{4} / \mathrm{C}$, the metal resource consumption for $\mathrm{LiFe}_{0.98} \mathrm{Mn}_{0.02} \mathrm{PO}_{4} / \mathrm{C}$, and the mineral refinement for $\mathrm{FeF}_{3}\left(\mathrm{H}_{2} \mathrm{O}\right)_{3} / \mathrm{C}$ show relatively low environmental sustainability. Three LCAs have little influence on total endpoint and element contribution values. However, at the midpoint level, the indicator with the lowest environmental sustainability for the same cathode materials is different in different methodologies.
\end{abstract}

Keywords: LIBs; environmental sustainability; cathode material; LCA

\section{Introduction}

With the expansion of the LIBs market, new cathode materials are constantly being developed [1]. In terms of weight fraction and cost, the cathode part for LIB is the most significant sector [2]. However, long-standing effort has been devoted to the development of high energy density and capability cathode materials [3], meeting the demand of electric vehicles, power tools, and large electric power storage units [4]. In fact, with the increase in energy density and capacity, many trace LIBs have an increasing impact on the environment [5]. Meanwhile, modern society must overcome many difficulties, such as obtaining natural resources and protecting the natural environment [4]. Before we commercialize a new cathode model, its environmental cost should be considered. Andersson confirmed the feasibility of environmental sustainability assessment in LCA for product development [6]. Numerous studies have quantified the impact of different types of LIB on the production process in its lifecycle [7]. Slowly, LCA is becoming more commonly used as a standardized method to determine the impact of a product or service on the environment throughout its whole life [8].

Although many new cathode models are being researched, the introduction of $\mathrm{LiCoO}_{2} / \mathrm{C}$ has enabled the commercialization of the first LIB [2]. LIBs have been available on the market from Sony 
Corp. since the early 1990s, and $\mathrm{LiCoO}_{2} / \mathrm{C}$ has become the leading $\mathrm{LIB}$ system [9]. $\mathrm{LiFePO}_{4} / \mathrm{C}$ stands as a competitive candidate cathode material for the next generation of a green and sustainable LIB system due to its long life span, abundant resources, low toxicity, and high thermal stability [10]. Meanwhile, the $\mathrm{LiFe}_{0.98} \mathrm{Mn}_{0.02} \mathrm{PO}_{4} / \mathrm{C}$, as an improved cathode material for $\mathrm{LiFePO}_{4} / \mathrm{C}$ [11], also shows promising development potential. As Zeng [12] confirmed, the electrochemical performance of $\mathrm{LiFePO}_{4} / \mathrm{C}$ was remarkably improved by a slight manganese substitution, creating the general formula $\mathrm{LiFe}_{X} \mathrm{Mn}_{1-X} \mathrm{PO}_{4} / \mathrm{C}$ [13]. However, most commercial cathode materials are $\mathrm{LiCoO}_{2} / \mathrm{C}$, whose actual capacity is $140-155 \mathrm{mAhg}^{-1}$, while $\mathrm{LiFePO}_{4} / \mathrm{C}$ or $\mathrm{LiFe}_{0.98} \mathrm{Mn}_{0.02} \mathrm{PO}_{4} / \mathrm{C}^{\prime}$ s theoretical capacity is only $170 \mathrm{mAhg}^{-1}$, so LIBs urgently need a new cathode model, like $\mathrm{FeF}_{3}\left(\mathrm{H}_{2} \mathrm{O}\right)_{3} / \mathrm{C}$ [14].

We can see that electrochemical properties $[15,16]$ have been the driving force for the development of different cathode materials. Many new studies have focused on electrochemical properties. However, due to the increasing prevalence of different cathode materials in electronic equipment and vehicles, their impact on the environment also needs to be considered [17]. Peters summarized the reviewed studies, focusing on energy demand and warming gas emissions for $\mathrm{LiCoO}_{2} / \mathrm{C}$ and $\mathrm{LiFePO}_{4} / \mathrm{C}$ [7]. Wang [18] evaluated the LIB with lithium-rich materials used in an electric vehicle throughout the life cycle of the battery. Wang [19] measured the carbon footprints of three industry lithium-ion secondary battery chains, and came to the conclusion that electric energy consumption is the main factor of lithium ion battery production companies in generating a carbon footprint. Liang [20] directly adopted LCA to assess the greenhouse gas emissions of LIBs. Deng [21] used LCA to assess high capacity molybdenum disulfide LIB for electric vehicles. Zackrission [22] elevated lithium-air batteries by LCA to quantify its climate impact, abiotic resource depletion and toxicity. Gong [23] evaluated four cathode materials by family footprint including carbon footprint and water footprint, and both direct and indirect water footprint [24].

In this paper, we not only pay attention to the total environmental sustainability of these four cathode materials, as previous studies have done, but also find that different indicators damage their environmental sustainability in different ways. Indeed, except for these common problems, certain indicators play different roles in specific cathode materials. In addition, from the results, we find that the different LCAs we choose have impacts on our evaluation. Based on the analysis of the calculation in three kinds of LCA, some suggestions are put forward for different cathodes, and the influence of different LCA is studied. There are three LCAs we chose for our study. Firstly, IMPACT 2002+ life cycle impact assessment methodology proposes a feasible implementation of a combined midpoint/damage approach, linking all types of life cycle inventory results (elementary flows and other interventions) via 14 midpoint categories to four damage categories, especially to human toxicity and ecotoxicity [25]. Secondly Eco-indicator 99(EI-99) is also used, a damage-oriented method to assess the emissions, extractions, and land use in all processes, and the damage to human health, ecosystem quality, and resources is calculated [26] ReCiPe assesses 18 impact categories at midpoint level (ozone depletion, human toxicity, etc.), and three endpoint categories (human health, ecosystems, resources) at endpoint level [27]. Based on these three LCAs, we divide the results into four innovative parts: (1) according to the total value of four different cathode materials, we have a preliminary understanding of the environmental sustainability ranking of these four cathode materials; (2) according to the endpoint value, we find one common environmental problem of the four cathode materials; (3) from the midpoint value, indicators showing the best or worst environmental sustainability of four cathode materials are summarized; (4) from the perspective of element contribution, the key elements that have obvious influence on the environmental sustainability of these four cathode materials are found. In fact, $\mathrm{LiCoO}_{2} / \mathrm{C}$ does not always show the lowest environmental sustainability among all indicators. The new cathode model $\mathrm{FeF}_{3}\left(\mathrm{H}_{2} \mathrm{O}\right)_{3} / \mathrm{C}$ also shows the lowest environmental sustainability in some respects. Although the chemical composition of $\mathrm{LiFe}_{0.98} \mathrm{Mn}_{0.02} \mathrm{PO}_{4} / \mathrm{C}$ is similar to that of $\mathrm{LiFePO}_{4} / \mathrm{C}$, the metal resource consumption for the former is far larger. Instead of focusing on the overall environmental sustainability, we care more about these specific indicators in different LCAs. 


\section{Materials and Methods}

\subsection{LCAs and Cathode Materials}

At present, IMPACT 2002+ and EI-99 have been widely recognized in many studies used to quantify the environmental impact of products [28]. Moreover, ReCiPe, as an improved LCA for EI-99, can evaluate more detailed indicators [29]. These three LCA methods are selected as the research methods. Although the results of environmental impacts are similar for equivalent categories, the ReCiPe and IMPACT 2002+ methods provide more categories for evaluation and comparison than EI-99 [30]. Furthermore, the assessment categories among these three LCAs are sufficient for us to make a comprehensive comparison. For example, the water issue is only evaluated in IMPACT 2002+, and acidification issues are only considered in both IMPACT 2002+ and EI-99. Indeed, there are many differences among these three LCAs, like the characterization of the unit and categories [31]. In addition, three cathode materials of $\mathrm{LIB}$ industry, $\mathrm{LiCoO}_{2} / \mathrm{C}, \mathrm{LiFePO}_{4} / \mathrm{C}$, and $\mathrm{LiFe}_{0.98} \mathrm{Mn}_{0.02} \mathrm{PO}_{4} / \mathrm{C}$, are selected as research objects. These three cathode models are marketed and mass produced every year. The evaluation of these major cathode materials is of great significance to the environmental sustainability development of LIBs. Furthermore, a new cathode model, $\mathrm{FeF}_{3}\left(\mathrm{H}_{2} \mathrm{O}\right)_{3} / \mathrm{C}$, is also evaluated as a comparison. The discovery of its environmental advantages can provide some enlightenment for these three market-oriented cathode models, which will help us to manufacture environmentally friendly cathode materials. Finally, the impact of different LCAs on sustainability assessment is also considered.

\subsection{Experimental Designation}

\subsubsection{Scope and Function Unit}

To compare the four cathode materials on the same basis, we should stipulate the scope and function unit of these four cathode materials. We only research the environmental impact of the cathode part. The original quality list comes from the existing literature and laboratory. After a normalized conversion, we make the quality list meet the functional unit $(1 \mathrm{~kg})$, which means that the mass of each cathode model we evaluated is equal.

\subsubsection{Experimental Devices}

This study is conducted by global LCA software Simapro released in 1990, and more than 80 countries have recognized its authority. Simapro allows researchers to collect, analyzes, and monitor the sustainability performance of products and services, from extraction of raw materials to manufacturing, distribution, use, and disposal [32]. In general, this includes (a) a user interface for modeling the product system, (b) a life cycle unit process database, (c) an impact assessment database with data supporting several life cycle impact assessment methodologies, and (d) a calculator that combines numbers from the databases in accordance with the modeling of the product system in the user interface [33].

\subsubsection{Experimental Process}

We researched these four cathodes at a deeper level. Of course, the total value of environmental sustainability for these four cathodes is shown in three LCAs. However, we also looked at endpoint values and midpoint values. In short, the lower the value is, the better the environmental sustainability. Finally, the element contribution proportion to endpoint and total values is calculated.

(1) Simulated Assembly

To meet the requirements of functional unit $(1 \mathrm{~kg})$, the original data were converted into a standard quality list. Then we assembled four complete cathode models in Simapro.

(2) Calculation 
To compare these four cathode materials, we have processed on the raw calculated data included in Supplementary Materials (Tables S1-S3), like normalization and contribution analysis. In fact, the data in the Supplementary Materials is calculated firstly by Simapro and all values has their own units which undoubtedly make it more difficult to compare these cathode materials. The detailed calculations of these four cathodes are listed as follows:

i. we calculate the total value of the four cathode materials by the entropy method, so that it satisfies a unit $(\mathrm{Pt})$.

ii. we calculate the values of all endpoint indicators in the unit $(\mathrm{Pt})$ and calculate their contribution to the total value.

iii. we calculate the values of all midpoint indicators and give the normalized values of all midpoint indicators in this paper. Material B has been a major market cathode in recent years, especially in the field of electric vehicles. We choose all values of midpoint indicators of material B as baseline 1 .

iv. we calculate the contribution ratio of elements at the endpoint and the total level.

Some indicators are simplified: the total value in three LCAs, $\operatorname{Ti}(\mathrm{i}=1,2,3)$; the endpoint indicators in different LCAs(IMPACT 2002+, Xm(m = 1, 2, 3, 4); EI-99, $\mathrm{Yn}(\mathrm{n}=1,2,3)$; ReCiPe, $\mathrm{Zh}(\mathrm{h}=1,2,3)$ ). The research process is shown in Figure 1.

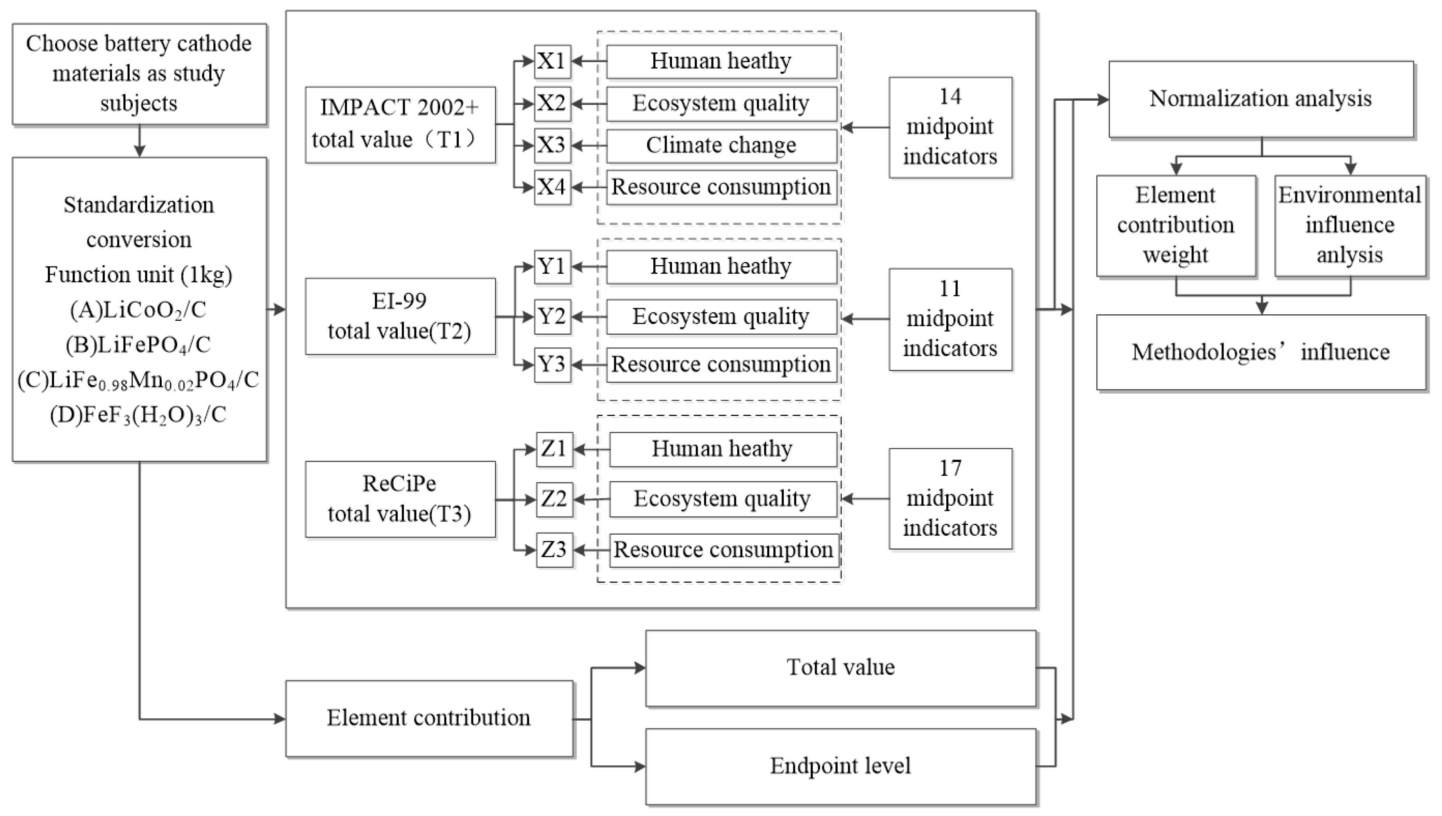

Figure 1. The research process.

\section{Results and Discussion}

\subsection{The Total Value of the Four Cathodes' Environmental Impact}

It is necessary to qualify the total environmental impact of these four cathode materials before a deeper investigation, because all midpoint and endpoint indicators are divided from the total environmental impact. Unlike Gong's research on evaluating environmental, economic, and electrochemical performance indicators by footprint family and Peters's summary focusing on energy demand and warming gas emissions for $\mathrm{LiCoO}_{2} / \mathrm{C}$ and $\mathrm{LiFePO}_{4} / \mathrm{C}$, we make a pure and further environmental assessment for these four cathode materials, and do not consider the economic benefits, electrochemical properties, energy demand, etc. This study aims to make a comprehensive assessment of these four typical cathodes directly. The total values for these four cathode materials in three LCAs are shown in Figure 2. 


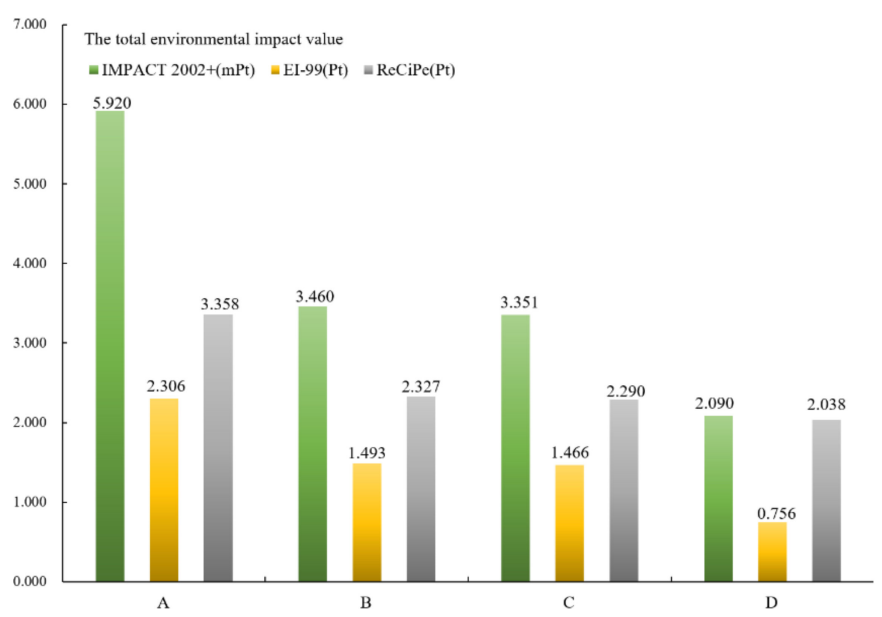

Figure 2. Total values for four cathodes in three LCAs: (A) $\mathrm{LiCoO}_{2} / \mathrm{C}$, (B) $\mathrm{LiFePO}_{4} / \mathrm{C}$, (C) $\mathrm{LiFe}_{0.98} \mathrm{Mn}_{0.02} \mathrm{PO}_{4} / \mathrm{C},(\mathbf{D}) \mathrm{FeF}_{3}\left(\mathrm{H}_{2} \mathrm{O}\right)_{3} / \mathrm{C}$.

As Figure 2 shows, we sort the four cathode types in descending order of environmental sustainability potential: D, C, B, and A. Although different LCAs have their own calculation standards, the trend of these four cathodes is the same. As Gong [23] confirms, D has the best environmental performance compared with $\mathrm{B}$ and $\mathrm{C}$. However, the study does not explain the differences in specific indicators between B, C, and D. More detailed indicators that are important for each of the three cathodes are found in this study. In addition, material A is added to the study as another major market cathode model. No matter what LCA we choose, the new cathode model D always presents the best potential for environmental sustainability, while material A performs the worst. The environmental sustainability of material B is close to that of material C. Methodological emphasis on environmental assessment is only reflected in quantitative values, rather than the qualitative environmental sustainable potential among these four cathodes.

\subsection{Endpoint Level}

To distinguish concrete environmental impacts of different cathode materials, we calculate all endpoint indicators in Table 1. In any LCA, material A always has the highest endpoint value among these four materials. D is the smallest. Except the resource consumption in ReCiPe, $0.449 \mathrm{Pt}$ of C larger than $0.393 \mathrm{Pt}$ of $\mathrm{B}$, other values for material B are slight larger than those for material C. IMPACT 2002+ and EI-99 have less impact on these four cathode materials' ranking of environmental sustainable potential. The resource consumption value between B and C calculated by ReCiPe is different to that calculated by the other two LCAs.

Table 1. Endpoint values for four cathodes.

\begin{tabular}{ccccc}
\hline \multirow{2}{*}{ Endpoint } & \multicolumn{4}{c}{ Indicator Value/Pt } \\
\cline { 2 - 5 } & $\mathbf{A}$ & $\mathbf{B}$ & $\mathbf{C}$ & $\mathbf{D}$ \\
\hline X1 & $2.510 \times 10^{-03}$ & $1.443 \times 10^{-03}$ & $1.423 \times 10-03$ & $0.779 \times 10^{-03}$ \\
X2 & $0.966 \times 10^{-03}$ & $0.093 \times 10^{-03}$ & $0.090 \times 10-03$ & $0.068 \times 10^{-03}$ \\
X3 & $1.278 \times 10^{-03}$ & $0.937 \times 10^{-03}$ & $0.900 \times 10-03$ & $0.555 \times 10^{-03}$ \\
X4 & $1.166 \times 10^{-03}$ & $0.988 \times 10^{-03}$ & $0.938 \times 10-03$ & $0.688 \times 10^{-03}$ \\
Y1 & 1.796 & 1.142 & 1.128 & 0.528 \\
Y2 & 0.101 & 0.042 & 0.041 & 0.035 \\
Y3 & 0.409 & 0.309 & 0.297 & 0.193 \\
Z1 & 2.697 & 1.875 & 1.784 & 1.747 \\
Z2 & 0.134 & 0.060 & 0.058 & 0.034 \\
Z3 & 0.527 & 0.393 & 0.449 & 0.258 \\
\hline
\end{tabular}

Note: refer all endpoints (X1-4; Y1-2; Z1-3) to Figure 1. 
The total value consists of the values of three or four endpoint indicators. To make a more intuitive observation, we calculated the contribution rates of different endpoint indexes to the total value, as shown in Figure 3. In three LCAs, the maximum contribution proportion of these four cathodes comes from human health. For material A, the contribution rate of ecosystem quality is relatively large in IMPACT $2002+$.

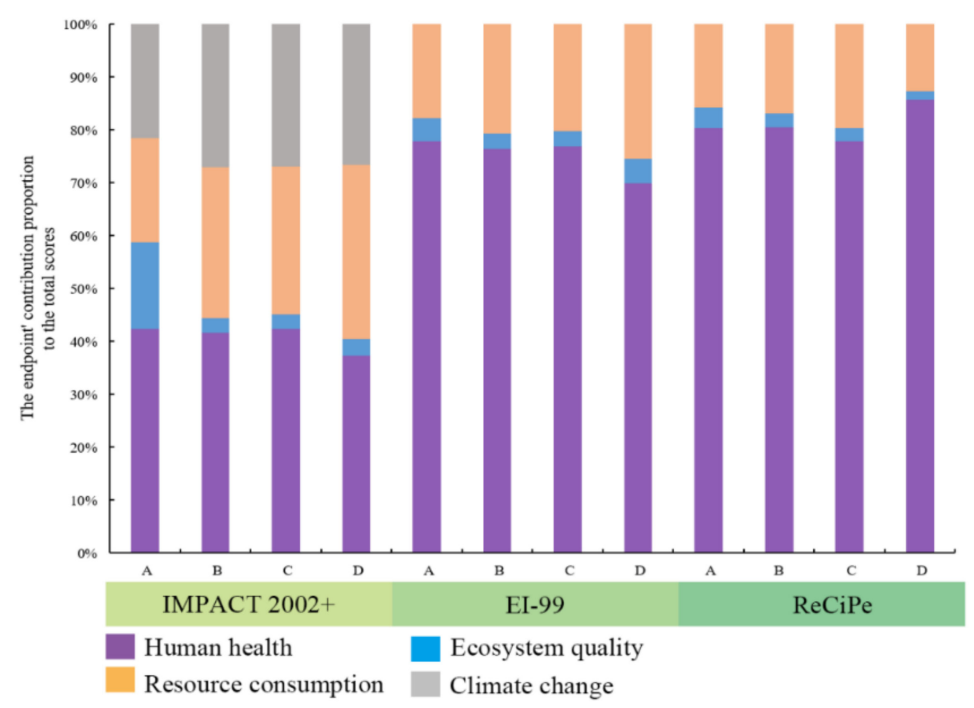

Figure 3. Endpoint indicators' contribution to the total value.

Obviously, in three LCAs, the environmental sustainability capacity for these four cathodes is related to human health, which means human health is a common problem for these four cathode materials to solve. In fact, Wanger [34] has confirmed that the effect of LIBs on human health is a common problem for LIBs. For the cathode, the effect on human health remains a major concern. Its existence may require a major technical improvement to overcome. For these individual problems in different cathodes, we can learn from the strengths and weaknesses of different cathodes. For example, material A always shows the largest environmental load in these four cathodes. Reducing its yield or finding alternative models, elements, or mechanisms is a feasible way to reduce its impact on ecosystem quality. As we know, IMPACT 2002+ and EI-99 have the same ranking for the environmental sustainability among these four cathode materials. Three LCAs show that the impact on human health is a common problem for these four cathode materials. However, in ReCiPe, material C consumes more resources compared with B. In IMPACT 2002+, material A's impact on ecosystem quality makes a relative contribution to its total environmental impact.

\subsection{Midpoint Level}

Similarly, each endpoint indicator can be divided into a number of midpoint indicators. In order to avoid interference from different units and magnitude, we choose all values of material $\mathrm{B}$ as the benchmark and normalize all values of the other three cathode materials. These indicators with an extreme value always show great disadvantages and advantages for different cathodes, and these normalized values, obviously larger or less than 1 , are more meaningful for individual cathode improvement. In IMPACT 2002+, the difference values between all normalized values and B' normalized value (1) are shown in Figure 4. In order to consider the impact of different LCA, we still give the unit of each midpoint indicator, reflecting their evaluation criteria. As we can see, there are 14 midpoint indicators, each of which has a different unit of measurement. To some extent, IMPACT 2002+ is more suitable for characterization evaluation. For example, we can use unit $\mathrm{kg} \mathrm{PO}_{4}$ p-lim to express the land use problem. Moreover, because of the presence of phosphorus, the data are meaningful for eutrophication. 


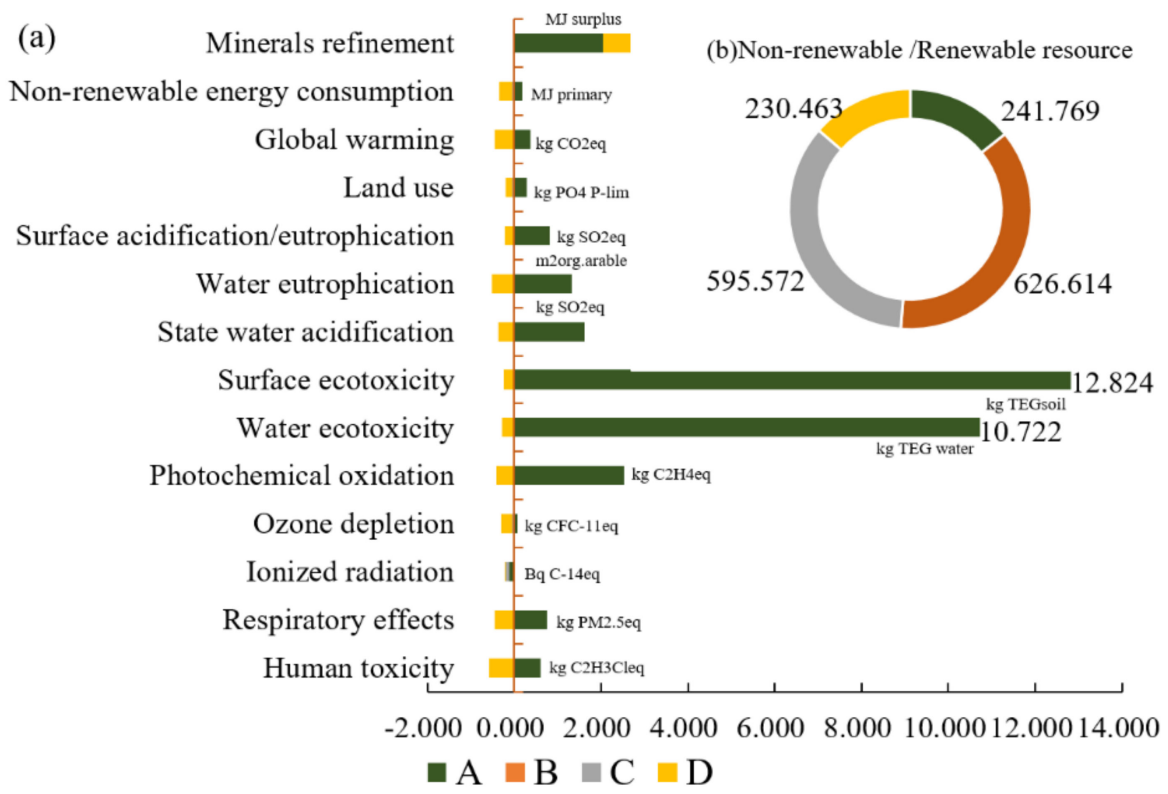

Figure 4. The normalized midpoint value in IMPACT 2002+.

As Figure 4 shows, when we regarded all normalized values of $B$ as the baseline, except for the value of ionized radiation, other normalized values of $A$ are larger than those of B. In particular, the eco-toxicity values of water body and surface are much larger, about 10.722 and 12.824, respectively. The high toxicity of cobalt may be the main reason for this situation. In fact, water problems and surface problems are difficult to completely separate, e.g., the toxicity of surface water. For water toxicity of A, water footprint assessment [35] may be a great method to quantify its water problems and reflect its toxicity from another perspective. For material D, except for the value for mineral refinement, other values are less than for B. Though D shows the best environmental sustainability, a green mineral refinement process is needed for material $D$. Finally, all normalized values for material C are slightly less than those for B. Material C, as an improved cathode to B by slight manganese substitution, has similar environmental sustainability potentiality to material $\mathrm{B}$. The close element composition between material $\mathrm{B}$ and $\mathrm{C}$, as the common formula shows, $\mathrm{LiFe}_{X} \mathrm{Mn}_{1-\mathrm{X}} \mathrm{PO}_{4} / \mathrm{C}(\mathrm{x}=0.98$ in this study), accounts for the similar environmental sustainability. IMPACT 2002+ shows a sensitive assessment for cathode $\mathrm{A}$, especially on water and surface ecotoxicity.

In EI-99, normalized values are shown in Figure 5. These indicators have the same cells separated from the same endpoint indicators. Compared with the IMPACT 2002+, these indicators cannot reflect specific substances due to their common units.
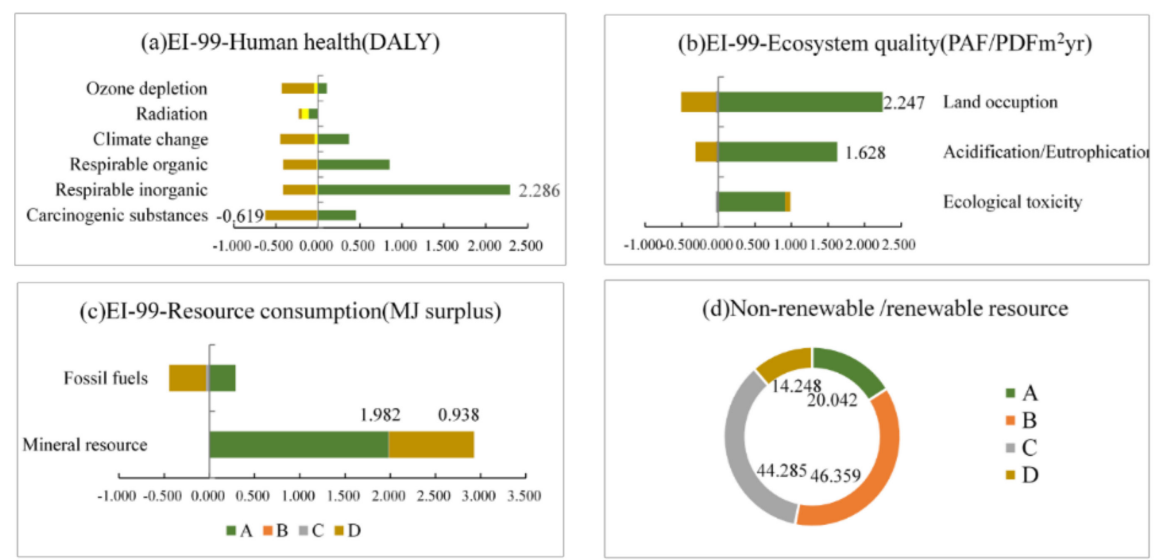

Figure 5. The normalized midpoint value in EI-99. 
As Figure 5a-c shows, except for the radiation value, the normalized value of $A$ is greater than that of $\mathrm{B}$, and the respiratory inorganic matter, land occupation, and mineral resource problems of A are obvious, at 2.286, 2.247, and 1.982, respectively. For D, its mineral resource value is far larger, about 0.938 . The ecological toxicity value is slightly larger. In addition to the mineral problems noted in IMPACT 2002+, the ecological toxicity of material D in EI-99 also becomes a low environmental sustainability index. Finally, all values of $C$ are close to 1, as IMPACT 2002+ shows.

In ReCiPe, all normalized values are shown in Figure 6. The midpoint indicators in ReCiPe are more detailed than EI-99. The unit for these indictors is different.

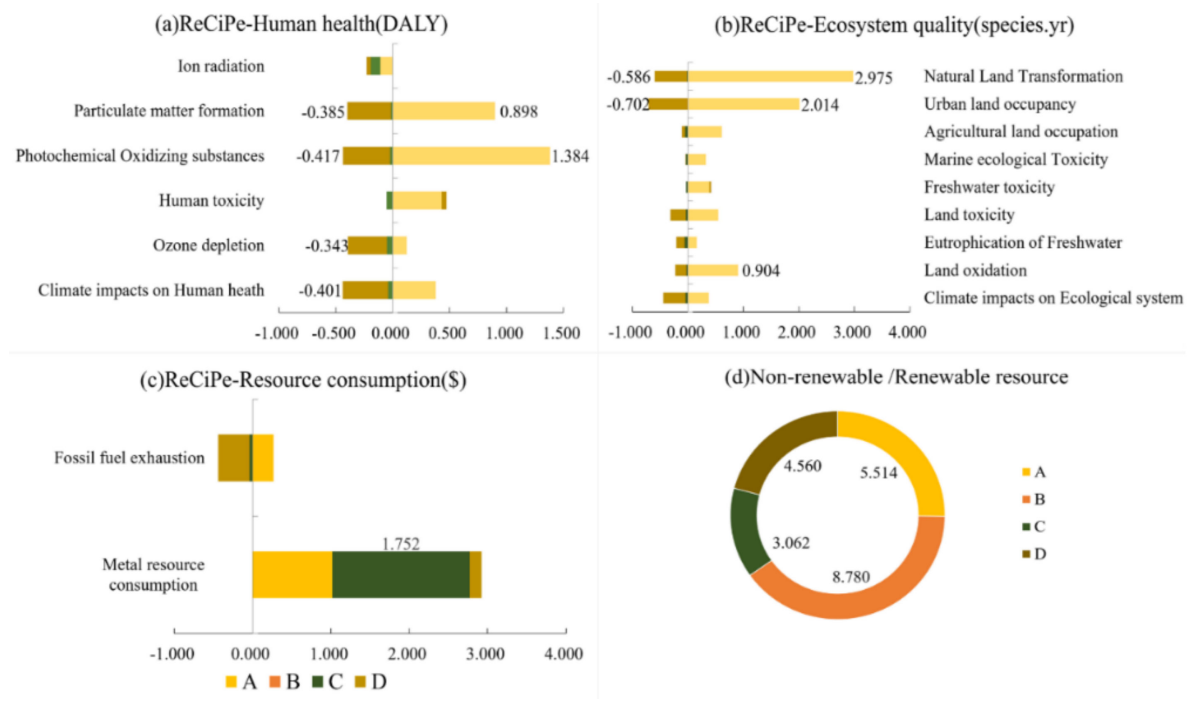

Figure 6. The normalized midpoint value in ReCiPe.

As Figure 6a-c shows, the normalized values of nature land transformation and urban land occupancy for material A are far larger, at 2.975 and, 2.014 respectively. Actually, material D performs very well on these two indicators, with -0.586 and -0.702 , respectively. Land occupation is an important part of the assessment of ecosystem quality [36]. That is a key difference between material A and D. For material C, not all normalized values are close to B, especially metal resource consumption, which is as high as 1.752. The method ReCiPe concentrates more on the economic costs (\$) in resource consumption [37], which means the economic cost in the slight manganese substitution process for material B needs to be cut down. To reduce the consumption of metal resources in the manganese substitution process must be a key issue for the development of material C. Finally, material D had low environmental sustainability in human toxicity, freshwater toxicity, and metal consumption compared with material B.

In addition, the problem of resource consumption deserves our attention. This endpoint in three LCAs is divided into two common midpoints, renewable and non-renewable resource consumption. We calculated the ratio of non-renewable resources to renewable ones. Mineral refinement in IMPACT 2002+, the mineral resource in EI-99 and the metal resource in ReCiPe are regarded as the renewable resource consumption. Likewise, the non-renewable energy, the fossil fuels and the fuel exhaustion are divided into the non-renewable resource consumption. The ratio is the non-renewable resources consumption per unit renewable resources consumption.

As Figures $4 \mathrm{~b}, 5 \mathrm{~d}$ and $6 \mathrm{~d}$ show, material $\mathrm{B}$ always has the highest ratio in three LCAs, 626.614 (MJ primary/MJ surplus) in IMPACT 2002+, 41.359 (MJ/MJ) in EI-99, 8.780 (\$/\$) in ReCiPe. That means every unit renewable resource consumption needs more non-renewable resource in the whole life cycle of material B. Material B has the lowest environmental sustainability among these four cathodes. More green processes with low non-renewable resource consumption are needed for material B. As worldwide concern about fossil fuels grows, efforts at non-renewable resource protection are urgently required [38]. These high ratios need to be reduced. Integrating the renewable resources in a 
small isolated power system, an isolated and complete battery [39], and improving the capacity for cathodes [40] are promising directions to achieve this goal.

Among the four cathode materials, the emphasis in the three LCAs is different. For material A, three LCAs all think that iron radiation is not a serious issue. The main problem in IMPACT 2002+ is ecotoxicity. On the contrary, EI-99 and ReCiPe think that the land issue is a serious issue. For materials $\mathrm{B}$ and $\mathrm{C}$, the values are mostly close to each other except for the metal resource consumption. For material D, three LCAs all show its low environmental sustainability in terms of mineral resource consumption, and its toxicity is noted in EI-99 and ReCiPe.

\subsection{The Element Contribution to Environmental Sustainability}

In this part, we use the elemental symbol to represent all elements in tables as follows: lithium (Li), cobalt $(\mathrm{Co})$, manganese $(\mathrm{Mn})$, iron $(\mathrm{Fe})$, fluorine $(\mathrm{F})$, nitrogen $(\mathrm{N})$, phosphorus $(\mathrm{P})$, and oxygen $(\mathrm{O})$. The contribution of the element to the endpoint and the total value is calculated.

\subsubsection{The Element Contribution in Endpoint Level}

In the three LCAs, the element contribution rate of material A is shown in Table 2. Cobalt is the largest contributor to ecosystem quality, followed by lithium. The other endpoint indexes were mainly affected by lithium, followed by cobalt. So cobalt impairs the environmental sustainability of material A in terms of ecosystem quality (endpoint) and land and toxicity issues (midpoint).

Table 2. The element contribution proportion for material A.

\begin{tabular}{ccccc}
\hline LCAs & Endpoint & Li & O & Co \\
\hline IMPACT 2002+ (\%) & X1 & 53.60 & 0.11 & 46.30 \\
& X2 & 8.30 & 0.01 & 91.70 \\
& X3 & 64.70 & 0.26 & 35.10 \\
EI-99 (\%) & X4 & 66.70 & 0.36 & 33.00 \\
& Y1 & 62.60 & 0.05 & 37.40 \\
ReCiPe (\%) & Y2 & 30.70 & 0.06 & 69.30 \\
& Y3 & 62.50 & 0.23 & 37.30 \\
& Z1 & 58.30 & 0.07 & 41.60 \\
& Z2 & 40.50 & 0.09 & 59.40 \\
& Z3 & 57.90 & 0.20 & 41.90 \\
\hline
\end{tabular}

For material B, the contribution rate of elements is shown in Table 3. The highest contribution proportion of each endpoint value always comes from lithium (the largest value is $\mathrm{Y} 1(83.70 \%)$, and the smallest value is Y2 $(60.50 \%)$ ), followed by phosphorus. Oxygen, iron, and nitrogen contribute little to each endpoint value.

Table 3. The element contribution proportion for material B.

\begin{tabular}{ccccccc}
\hline LCAs & Endpoint & Li & O & Fe & N & P \\
\hline IMPACT 2002+ (\%) & X1 & 78.20 & 0.91 & 1.14 & 2.28 & 17.5 \\
& X2 & 72.40 & 0.28 & 3.09 & 3.31 & 20.9 \\
& X3 & 74.10 & 1.63 & 0.16 & 4.41 & 19.7 \\
& X4 & 66.00 & 1.96 & 0.16 & 5.73 & 26.2 \\
EI-99 (\%) & Y1 & 83.70 & 0.42 & 1.81 & 1.34 & 12.7 \\
& Y2 & 60.50 & 0.81 & 0.40 & 3.18 & 35.1 \\
\multirow{2}{*}{ ReCiPe (\%) } & Y3 & 69.50 & 1.40 & 0.40 & 4.44 & 24.3 \\
& Z1 & 70.40 & 0.49 & 0.34 & 5.64 & 23.2 \\
& Z2 & 76.20 & 0.97 & 0.17 & 3.84 & 18.9 \\
& Z3 & 65.20 & 1.25 & 6.09 & 4.27 & 23.2 \\
\hline
\end{tabular}


Table 4 shows the element contribution rate of material C. The highest contribution rate of element to each endpoint value is still lithium, followed by phosphorus. The rest of the elements have less weight.

Table 4. The element contribution proportion for material C.

\begin{tabular}{cccccccc}
\hline LCAs & Endpoint & Li & Fe & O & N & P & Mn \\
\hline IMPACT 2002+ (\%) & X1 & 79.30 & 1.16 & 0.93 & 0.18 & 17.70 & 0.72 \\
& X2 & 74.30 & 3.17 & 0.28 & 0.27 & 21.50 & 0.47 \\
& X3 & 77.00 & 0.17 & 1.71 & 0.36 & 20.50 & 0.23 \\
EI-99 (\%) & X4 & 69.50 & 0.17 & 2.08 & 0.48 & 27.60 & 0.25 \\
& Y1 & 83.60 & 1.72 & 0.40 & 0.14 & 13.80 & 0.34 \\
& Y2 & 63.50 & 0.34 & 0.66 & 0.31 & 33.90 & 1.29 \\
$\operatorname{ReCiPe~(\% )~}$ & Y3 & 72.20 & 0.42 & 1.47 & 0.37 & 25.20 & 0.29 \\
& Z1 & 73.90 & 0.36 & 0.52 & 0.47 & 24.30 & 0.37 \\
& Z2 & 78.50 & 0.18 & 1.00 & 0.31 & 19.50 & 0.53 \\
& Z3 & 57.00 & 5.33 & 1.10 & 0.30 & 20.30 & 16.00 \\
\hline
\end{tabular}

Finally, the element contribution proportion for material D is showed in Table 5. As a non-lithium composition model (no lithium in quality list), fluorine has the highest contribution rate among all mid-point indicators, at almost $90.00 \%$.

Table 5. The element contribution proportion for material D.

\begin{tabular}{ccccc}
\hline LCAs & Endpoint & Fe & O & F \\
\hline IMPACT 2002+ (\%) & X1 & 1.78 & 1.47 & 96.80 \\
& X2 & 3.55 & 0.33 & 96.10 \\
& X3 & 0.23 & 2.39 & 97.40 \\
EI-99 (\%) & X4 & 0.19 & 2.44 & 97.40 \\
& Y1 & 3.08 & 0.73 & 96.20 \\
ReCiPe (\%) & Y2 & 0.33 & 0.66 & 99.00 \\
& Y3 & 0.54 & 1.95 & 97.50 \\
& Z1 & 0.31 & 0.46 & 99.20 \\
& Z2 & 0.25 & 1.47 & 98.30 \\
& Z3 & 7.81 & 1.64 & 90.50 \\
\hline
\end{tabular}

Some issues can be found by the element contribution. The ecosystem quality in material A is mainly affected by cobalt. To seek a substitute material or reduce the quality of cobalt in production process will be a method to improve its environmental sustainability. As one heavy metal element, cobalt has higher ecosystem toxicity and pollution capacity than other elements in the four cathode materials. This is why many efforts to recover A are concentrated not only on lithium but also on cobalt [41]. There are two examples of Co substitutes. Xiang [42] improved the electrochemical kinetics of lithium manganese phosphate via Co-substitution. Di Lecce [43] investigated a new $\mathrm{Sn}-\mathrm{C} / \mathrm{LiFe}_{0.1} \mathrm{Co}_{0.9} \mathrm{PO}_{4}$ full lithium-ion cell with ionic liquid-based electrolyte. The two studies demonstrated the feasibility of producing Co-substitutes and for improving the environmental sustainability for A.

Except the ecosystem quality for material A mainly affected by cobalt, others indicators' environmental sustainability for materials $A, B$ and $C$ is mainly affected by lithium. However, the phosphorus in material $\mathrm{B}$ and $\mathrm{C}$ also has a great impact on their environmental sustainability. Reducing the consumption of lithium is an ongoing aim in the development for LIBs. More research on cobalt and phosphorus is also needed. All three LCAs show the same result-that is, different LCAs have no influence on the determination of the main elements contributing to the endpoint index values. 
3.4.2. The Element Contribution to the Total Value

The element proportions in the total level are shown in Figure 7.

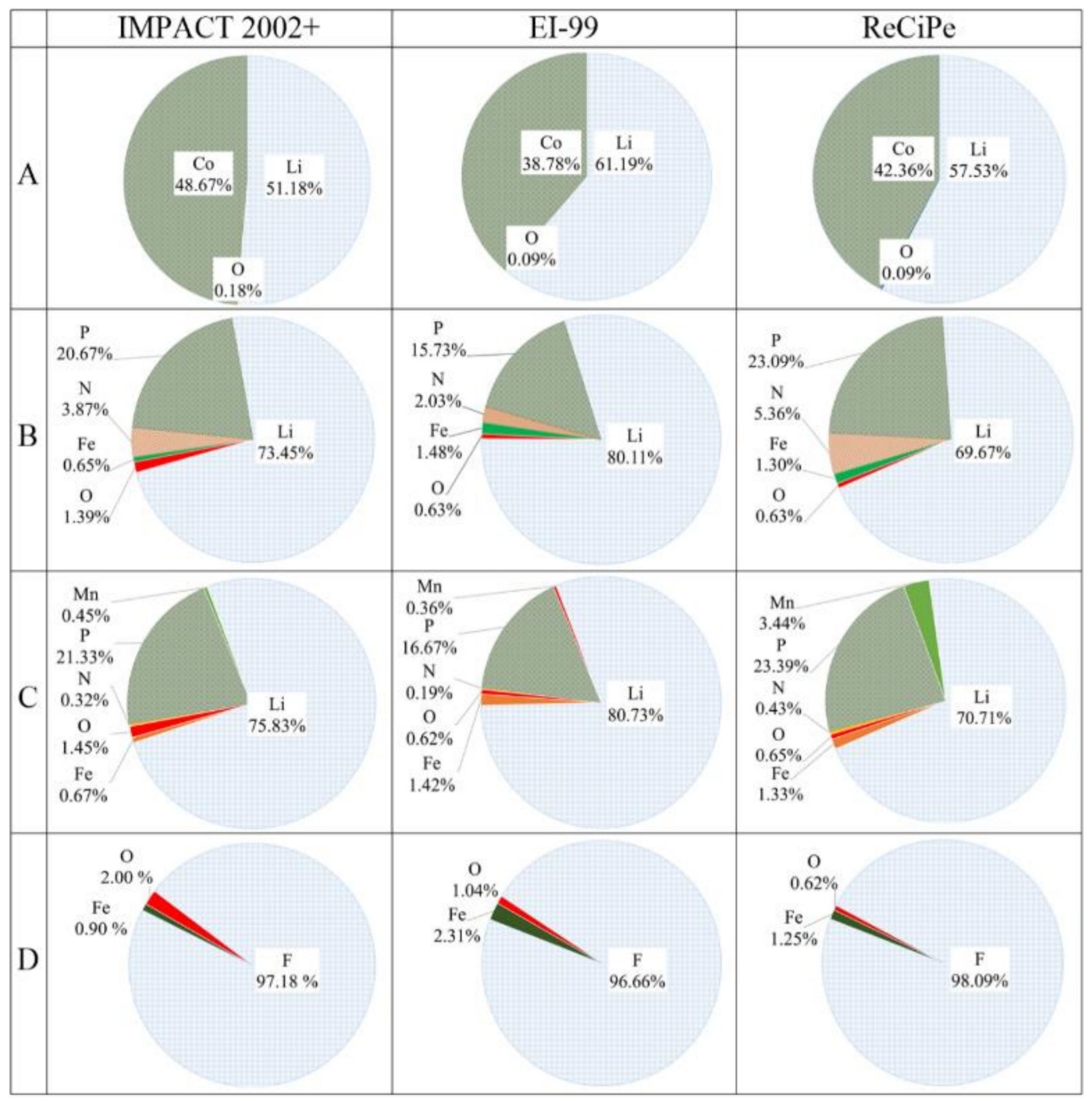

Figure 7. The element contribution proportion to the total values in three LCAs.

In all LCAs, the largest contribution to the total value in materials $\mathrm{A}, \mathrm{B}$ and $\mathrm{C}$ comes from lithium, up to $80.00 \%$ in EI-99 for materials B and C. For material D, it comes from the element fluorine, at around $90.00 \%$ in three LCAs. Moreover, the second contribution element for material A is cobalt, at 38.78\% in EI-99 and 48.67\% in IMPACT 2002+. For materials B and C it is phosphorus, at about $20.00 \%$. Other elements made just a small contribution to the total values, less than $5.00 \%$. This result is consistent with Yang's [44] research that there is significant waste of valuable metallic resources in LIBs and the environmental load of lithium consumption is the largest among all elements. Furthermore, except for the contribution of lithium, phosphorus plays an important role in the environmental sustainability potential of materials B and C. For material A, the influence of cobalt also cannot be ignored.

\subsection{The Methodologies' Influence to Environmental Sustainability Assessment}

Based on the discussion at the above four levels, we find that these four cathodes have different environmental sustainability potential due to the different LCA we use. 
(1) Different LCAs have little impact on the environmental sustainability assessment of the total, endpoint, and element levels of the four cathodes. The environmental sustainability of $\mathrm{FeF}_{3}\left(\mathrm{H}_{2} \mathrm{O}\right)_{3} / \mathrm{C}$ is better than $\mathrm{LiFe}_{0.98} \mathrm{Mn}_{0.02} \mathrm{PO}_{4} / \mathrm{C}$, which is better than $\mathrm{LiFePO}_{4} / \mathrm{C}$ and $\mathrm{LiCoO}_{2} / \mathrm{C}$.

(2) The environmental sustainability of the four cathode types is mainly affected by human health. Lithium is the largest contributor to the environmental load of the first three market cathodes. However, for $\mathrm{FeF}_{3}\left(\mathrm{H}_{2} \mathrm{O}\right)_{3} / \mathrm{C}$, fluorine is the largest contributor to its environmental load.

(3) At the midpoint level, the four cathodes show different environmental sustainability in concrete indicators due to the different LCAs we chose. The mineral resource consumption of $\mathrm{FeF}_{3}\left(\mathrm{H}_{2} \mathrm{O}\right)_{3} / \mathrm{C}$, the metal resource consumption of $\mathrm{LiFe}_{0.98} \mathrm{Mn}_{0.02} \mathrm{PO}_{4} / \mathrm{C}$, high non-renewable resource consumption of $\mathrm{LiFePO}_{4} / \mathrm{C}$, and the toxicity and land issues of $\mathrm{LiCoO}_{2} / \mathrm{C}$ have seriously affected their environmental sustainability. Furthermore, the cobalt in $\mathrm{LiCoO}_{2} / \mathrm{C}$, because of its ecosystem quality, and the phosphorus in $\mathrm{LiFePO}_{4} / \mathrm{C}$ and $\mathrm{LiFe}_{0.98} \mathrm{Mn}_{0.02} \mathrm{PO}_{4} / \mathrm{C}$ also obviously impair the environmental sustainability at the midpoint level.

\section{Conclusions}

Different LCAs show different quantitative results in these four cathode materials. Qualitative assessments of these three LCAs is similar, both in terms of contributing elements and the total value. At the endpoint level, except for the resource consumption for $\mathrm{LiFe}_{0.98} \mathrm{Mn}_{0.02} \mathrm{PO}_{4} / \mathrm{C}$ and $\mathrm{LiFePO}_{4} / \mathrm{C}$ in ReCiPe, the ranking of other indicators' values is consistent with the total values. Four cathode models are ranked in descending order of environmental sustainability potential: $\mathrm{FeF}_{3}\left(\mathrm{H}_{2} \mathrm{O}\right)_{3} / \mathrm{C}, \mathrm{LiFe}_{0.98} \mathrm{Mn}_{0.02} \mathrm{PO}_{4} / \mathrm{C}, \mathrm{LiFePO}_{4} / \mathrm{C}$, and $\mathrm{LiCoO}_{2} / \mathrm{C}$. At the midpoint level, most indicators are consistent with the ranking. However, the most serious problem is determined differently based on different methodologies.

Supplementary Materials: The following are available online at www.mdpi.com/2227-9717/7/2/83/s1, Table S1: Calculation for mid point indicators in IMPACT 2002+, Table S2: Calculation for midpoint indicators in EI-99, Table S3: Calculation for midpoint indicators in ReCiPe.

Author Contributions: Conceptualization, L.W. and H.W.; Methodology, L.W. and H.W.; Software, Y.Y.; Validation, Y.Y. and K.H.; Formal Analysis, H.W. and Y.Y.; Investigation, L.W. and H.W.; Resources, Y.Y.; Writing-Original Draft Preparation, L.W.; Writing-Review and Editing, L.W. and H.W.; Visualization, L.W. and H.W.; Supervision, Y.Y. and K.H.; Project Administration, Y.Y. and K.H.; Funding Acquisition, Y.Y. and K.H.

Funding: This research was funded by: The Fundamental Research Funds for the Central Universities of China (No. 2018BLCB-05), the National Natural Science Foundation of China (No. 51474033), and Beijing Natural Science Foundation (9172012).

Conflicts of Interest: The authors declare no conflict of interest.

\section{References}

1. Swart, P.; Dewulf, J.; Biernaux, A. Resource demand for the production of different cathode materials for lithium ion batteries. J. Clean. Prod. 2014, 84, 391-399. [CrossRef]

2. Zhu, X.; Lin, T.; Manning, E.; Zhang, Y.; Yu, M.; Zuo, B.; Wang, L. Recent advances on Fe- and Mn-based cathode materials for lithium and sodium ion batteries. J. Nanoparticle Res. 2018, 20, 160. [CrossRef]

3. Chakraborty, S.; Banerjee, A.; Watcharatharapong, T.; Araujo, R.B.; Ahuja, R. Current computational trends in polyanionic cathode materials for Li and Na batteries. J. Phys. Condens. Matter: Inst. of Phys. J. 2018, 30, 283003. [CrossRef] [PubMed]

4. Jeong, G.; Kim, Y.-U.; Kim, H.; Kim, Y.-J.; Sohn, H.-J. Prospective materials and applications for li secondary batteries. Energy Environ. Sci. 2011, 4, 1986. [CrossRef]

5. Cerdas, F.; Titscher, P.; Bognar, N.; Schmuch, R.; Winter, M.; Kwade, A.; Herrmann, C. Exploring the effect of increased energy density on the environmental impacts of traction batteries: A comparison of energy optimized lithium-ion and lithium-sulfur batteries for mobility applications. Energies 2018, 11, 150. [CrossRef] 
6. Andersson, K.; Eide, M.H. The feasibility of including sustainability in lca for product development. J. Clean. Prod. 1998, 6, 289-298. [CrossRef]

7. Peters, J.F.; Baumann, M.; Zimmermann, B.; Braun, J.; Weil, M. The environmental impact of li-ion batteries and the role of key parameters-A review. Renew. Sustain. Energy Rev. 2017, 67, 491-506. [CrossRef]

8. Peters, J.F.; Weil, M. Providing a common base for life cycle assessments of Li-ion batteries. J. Clean. Prod. 2018, 171, 704-713. [CrossRef]

9. Li, L.; Dunn, J.B.; Zhang, X.X.; Gaines, L.; Chen, R.J.; Wu, F.; Amine, K. Recovery of metals from spent lithium-ion batteries with organic acids as leaching reagents and environmental assessment. J. Power Sources 2013, 233, 180-189. [CrossRef]

10. Yuan, L.X.; Wang, Z.H.; Zhang, W.X.; Hu, X.L.; Chen, J.T.; Huang, Y.H.; Goodenough, J.B. Development and challenges of lifepo4 cathode material for lithium-ion batteries. Energy Environ. Sci. 2011, 4, 269-284. [CrossRef]

11. Lin, Y.; Zeng, B.; Lin, Y.; Li, X.; Zhao, G.; Zhou, T.; Lai, H.; Huang, Z. Electrochemical properties of carbon-coated lifepo4 and $\mathrm{LiFe}_{0.98} \mathrm{Mn}_{0.02} \mathrm{PO}_{4}$ cathode materials synthesized by solid-state reaction. Rare Met. 2012, 31, 145-149. [CrossRef]

12. Zeng, L.; Gong, Q.; Liao, X.; He, L.; He, Y.; Ma, Z. Enhanced low-temperature performance of slight Mn-substituted lifepo4/c cathode for lithium ion batteries. Chin. Sci. Bull. 2011, 56, 1262-1266. [CrossRef]

13. Togo, M.; Nakahira, A. Structure refinement of mn-substituted $\mathrm{LiMn}_{\mathrm{x}} \mathrm{Fe}_{1-\mathrm{x}} \mathrm{PO}_{4}$. Mater. Sci. Appl. 2018, 09, 542-553.

14. Wu, C.; Li, X.X.; Wu, F.; Bai, Y.; Chen, M.Z.; Zhong, Y. Composite $\mathrm{FeF}_{3} \bullet 3 \mathrm{H}_{2} \mathrm{O} / \mathrm{C}$ cathode material for lithium ion battery. Adv. Mater. Res. 2011, 391-392, 1090-1094. [CrossRef]

15. Ludwig, J.; Nilges, T. Recent progress and developments in lithium cobalt phosphate chemistry- syntheses, polymorphism and properties. J. Power Sources 2018, 382, 101-115. [CrossRef]

16. Pfleging, W. A review of laser electrode processing for development and manufacturing of lithium-ion batteries. Nanophotonics 2018, 7, 549-573. [CrossRef]

17. Winslow, K.M.; Laux, S.J.; Townsend, T.G. A review on the growing concern and potential management strategies of waste lithium-ion batteries. Resour. Conserv. Recycl. 2018, 129, 263-277. [CrossRef]

18. Wang, Y.; Yu, Y.; Huang, K.; Chen, B.; Deng, W.; Yao, Y. Quantifying the environmental impact of a Li-rich high-capacity cathode material in electric vehicles via life cycle assessment. Environ. Sci. Pollut. Res. Int. 2017, 24, 1251-1260. [CrossRef]

19. Wang, C.; Chen, B.; Yu, Y.; Wang, Y.; Zhang, W. Carbon footprint analysis of lithium ion secondary battery industry: Two case studies from China. J. Clean. Prod. 2017, 163, 241-251. [CrossRef]

20. Liang, Y.; Su, J.; Xi, B.; Yu, Y.; Ji, D.; Sun, Y.; Cui, C.; Zhu, J. Life cycle assessment of lithium-ion batteries for greenhouse gas emissions. Resour. Conserv. Recycl. 2017, 117, 285-293. [CrossRef]

21. Deng, Y.; Li, J.; Li, T.; Zhang, J.; Yang, F.; Yuan, C. Life cycle assessment of high capacity molybdenum disulfide lithium-ion battery for electric vehicles. Energy 2017, 123, 77-88. [CrossRef]

22. Zackrisson, M.; Fransson, K.; Hildenbrand, J.; Lampic, G.; O’Dwyer, C. Life cycle assessment of lithium-air battery cells. J. Clean. Prod. 2016, 135, 299-311. [CrossRef]

23. Gong, Y.; Yu, Y.; Huang, K.; Hu, J.; Li, C. Evaluation of lithium-ion batteries through the simultaneous consideration of environmental, economic and electrochemical performance indicators. J. Clean. Prod. 2018, 170, 915-923. [CrossRef]

24. Xu, Y.J.; Huang, K.; Yu, Y.J.; Wang, X.M. Changes in water footprint of crop production in beijing from 1978 to 2012: A logarithmic mean divisia index decomposition analysis. J. Clean. Prod. 2015, 87, 180-187. [CrossRef]

25. Jolliet, O.; Margni, M.; Charles, R.; Humbert, S.; Payet, J.; Rebitzer, G.; Rosenbaum, R. Impact 2002+: A new life cycle impact assessment methodology. Int. J. Life Cycle Assess. 2003, 8, 324-330. [CrossRef]

26. Audenaert, A.; De Cleyn, S.H.; Buyle, M. Lca of low-energy flats using the eco-indicator 99 method: Impact of insulation materials. Energy Build. 2012, 47, 68-73. [CrossRef]

27. Lamnatou, C.; Motte, F.; Notton, G.; Chemisana, D.; Cristofari, C. Building-integrated solar thermal system with/without phase change material: Life cycle assessment based on recipe, usetox and ecological footprint. J. Clean. Prod. 2018, 193, 672-683. [CrossRef]

28. Henclik, A.; Bajdur, W.M. Application of selected methods of life cycle assessment to judgment of environmental hazard of production process of flocculant synthesized from waste phenol-formaldehyde resin. Rocz. Ochr. Sr. 2011, 13, 1809-1822. 
29. Lamnatou, C.; Baig, H.; Chemisana, D.; Mallick, T.K. Environmental assessment of a building-integrated linear dielectric-based concentrating photovoltaic according to multiple life-cycle indicators. J. Clean. Prod. 2016, 131, 773-784. [CrossRef]

30. Cavalett, O.; Chagas, M.F.; Seabra, J.E.A.; Bonomi, A. Comparative lca of ethanol versus gasoline in Brazil using different lcia methods. Int. J. Life Cycle Assess. 2012, 18, 647-658. [CrossRef]

31. Owsianiak, M.; Laurent, A.; Bjørn, A.; Hauschild, M.Z. Impact 2002+, recipe 2008 and ilcd's recommended practice for characterization modelling in life cycle impact assessment: A case study-based comparison. Int. J. Life Cycle Assess. 2014, 19, 1007-1021. [CrossRef]

32. Starostka-Patyk, M. New products design decision making support by simapro software on the base of defective products management. Procedia Comput. Sci. 2015, 65, 1066-1074. [CrossRef]

33. Herrmann, I.T.; Moltesen, A. Does it matter which life cycle assessment (lca) tool you choose? A comparative assessment of simapro and gabi. J. Clean. Prod. 2015, 86, 163-169. [CrossRef]

34. Wanger, T.C. The lithium future-resources, recycling, and the environment. Conserv. Lett. 2011, 4, $202-206$. [CrossRef]

35. Zhang, Y.; Huang, K.; Yu, Y.J.; Yang, B.B. Mapping of water footprint research: A bibliometric analysis during 2006-2015. J. Clean. Prod. 2017, 149, 70-79. [CrossRef]

36. Koellner, T. Land use in product life cycles and its consequences for ecosystem quality. Int. J. Life Cycle Assess. 2002, 7, 130-130. [CrossRef]

37. Klinglmair, M.; Sala, S.; Brandão, M. Assessing resource depletion in lca: A review of methods and methodological issues. Int. J. Life Cycle Assess. 2013, 19, 580-592. [CrossRef]

38. Li, W.; Song, B.; Manthiram, A. High-voltage positive electrode materials for lithium-ion batteries. Chem. Soci. Rev. 2017, 46, 3006-3059. [CrossRef]

39. Branco, H.; Castro, R.; Setas Lopes, A. Battery energy storage systems as a way to integrate renewable energy in small isolated power systems. Energy Sustain. Dev. 2018, 43, 90-99. [CrossRef]

40. Li, Y.; Yang, J.; Song, J. Design structure model and renewable energy technology for rechargeable battery towards greener and more sustainable electric vehicle. Renew. Sustain. Energy Rev. 2017, 74, 19-25. [CrossRef]

41. Peng, C.; Hamuyuni, J.; Wilson, B.P.; Lundstrom, M. Selective reductive leaching of cobalt and lithium from industrially crushed waste Li-ion batteries in sulfuric acid system. Waste Manag. 2018, 76, 582-590. [CrossRef] [PubMed]

42. Xiang, W.; Zhong, Y.; Tang, Y.; Shen, H.; Wang, E.; Liu, H.; Zhong, B.; Guo, X. Improving the electrochemical kinetics of lithium manganese phosphate via co-substitution with iron and cobalt. J. Alloys Compd. 2015, 635, 180-187. [CrossRef]

43. Di Lecce, D.; Brutti, S.; Panero, S.; Hassoun, J. A new sn-c/life0.1co0.9po4 full lithium-ion cell with ionic liquid-based electrolyte. Mater. Lett. 2015, 139, 329-332. [CrossRef]

44. Yang, Y.; Meng, X.; Cao, H.; Lin, X.; Liu, C.; Sun, Y.; Zhang, Y.; Sun, Z. Selective recovery of lithium from spent lithium iron phosphate batteries: A sustainable process. Green Chem. 2018, 20, 3121-3133. [CrossRef]

(C) 2019 by the authors. Licensee MDPI, Basel, Switzerland. This article is an open access article distributed under the terms and conditions of the Creative Commons Attribution (CC BY) license (http://creativecommons.org/licenses/by/4.0/). 